\title{
Aspectos da hidratação de óxido de magnésio em formulações de concretos refratários
}

\section{(Aspects of magnesium oxide hydration in $r$ efractory castables compositions)}

\author{
R. Salomão ${ }^{1}$, L. R. M. Bittencourt ${ }^{2}$, V. C. Pandolfelli ${ }^{1}$ \\ Departamento de Engenharia de Materiais - DEMa \\ Universidade Federal de S. Carlos - UFSCar \\ Rod. Washington Luiz, km 235, C.P. 676, S. Carlos, SP 13565-905 \\ pers@iris.ufscar.br,vicpando@power.ufscar.br \\ ${ }^{2}$ Centro de Pesquisas - Magnesita S.A. \\ Praça Louis Ensch, 240 \\ Contagem, MG 32210-050
}

\begin{abstract}
Resumo
Óxido de magnésio $(\mathrm{MgO})$ ou magnésia é uma das matérias primas mais importantes para a indústria de refratários. Graças à sua elevada refratariedade (ponto de fusão da ordem de $2800^{\circ} \mathrm{C}$ ) e resistência à corrosão me meios básicos, associadas a custos relativamente baixos, sua utilização em tijolos permitiu um significativo aumento no desempenho e durabilidade desses materiais. No entanto, como uma seqüência natural da utilização desse material, seu uso em concretos refratários não obteve o mesmo impacto em aplicações industriais devido à sua elevada tendência em reagir com água e a decorrente expansão volumétrica gerada. Desse modo, adições de magnésia em concretos têm sido restritas a baixos teores ( $>10 \%$ peso) e ao uso de partículas grosseiras $(\geq 100$ $\mu \mathrm{m})$. Neste trabalho, foram analisados criteriosamente os diversos estudos referentes à hidratação do $\mathrm{MgO}$ em concretos refratários, o impacto gerado nas diferentes etapas de processamento desses materiais e as técnicas empregadas para evitá-la.
\end{abstract}

Palavras-chave: concretos refratários, óxido de magnésio, magnésia, hidratação.

\begin{abstract}
Magnesium oxide $(\mathrm{MgO})$ or magnesia is one of the most important raw materials for the refractories industry. Because of high refractoriness (melting point of $2800^{\circ} \mathrm{C}$ ), corrosion resistance in basic environments and relatively low costs, its use in bricks has allowed a significant increase in the performance and service life of these materials. However, its use in refractory castables did not attain the same impact in industrial applications because of its great tendency in react with water and the consequent volumetric expansion generated. Therefore, magnesia additions in castables has been kept in small amounts (bellow 10 wt\%) and restricted to large particles $(\geq 100 \mu \mathrm{m})$. In the present work, several reports on magnesia hydration in refractory castables, its effects on the castables processing and the anti-hydration techniques were critically reviewed.
\end{abstract}

Keywords: refractory castables, magnesium oxide, magnesia, hydration.

\section{INTRODUÇÃO}

Após enfrentar um período de recessão nas décadas de 70 e 80 , a indústria siderúrgica viu-se obrigada a realizar uma série de modificações conceituais em seu sistema de produção $[1,2]$. Afetados por essa mudança, os produtores de refratários também foram obrigados a se adaptar à nova realidade. Com a evolução no desenvolvimento desses materiais, os usuários obtiveram melhor desempenho, o que resultou na redução do consumo de refratários por tonelada de aço produzido e no aumento de seu valor agregado [2].

$\mathrm{O}$ aumento do desempenho dos materiais refratários está relacionado a dois fatores principais [2]. O primeiro foi o desenvolvimento dos tijolos refratários de magnésia e magnésia-carbono. Comparando com outras classes de refratários, estas apresentam elevada refratariedade, resistência termo-mecânica e à corrosão, aliados a um custo relativamente reduzido. $\mathrm{O}$ segundo fator está relacionado ao grande avanço na tecnologia de produção e instalação dos refratários monolíticos, graças à utilização de matérias primas mais nobres e de novas técnicas de formulação e empacotamento, além de novos tipos de dispersantes. A versatilidade desses materiais, principalmente dos concretos refratários, permite grande liberdade de projeto aliada a rapidez e baixos custos de instalação.

No entanto, após 1995, o número de patentes registradas 

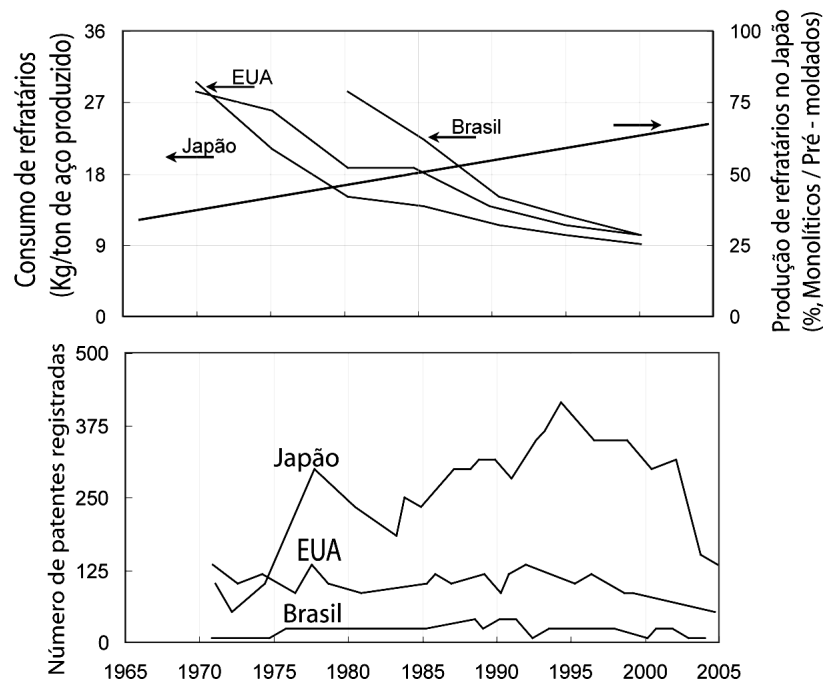

Figura 1: Evolução do a) consumo de refratários e b) do número de patentes registradas.

[Figure 1: Evolution on a) refractories consumption and b) number of issued patents.]

sobre esses dois tópicos tem sido reduzido, ano após ano [2]. Esse fato indica que, embora funcionais e com ótimo desempenho, essas tecnologias atingiram seu limite de desenvolvimento. Deu-se lugar, portanto, as inovações menores ou não patenteáveis, enquanto aquelas de alto impacto permanecem ainda no estágio de pesquisa. É nesse contexto que se insere o desenvolvimento de concretos refratários contendo óxido de magnésio $[1,2]$.

Após cuidadosa revisão de grande parte da literatura que versa sobre mecanismos de hidratação do $\mathrm{MgO}$ e sua adição em formulações de concretos refratários, notou-se a ausência de estudos sistemáticos sobre o assunto [1]. A importância industrial desses materiais sugere que, embora tenham alto interesse tecnológico, sua produção é complexa devido às muitas variáveis envolvidas dos segredos industriais e à carência de uma abordagem científica, contínua e sistêmica.

As poucas publicações disponíveis apontam que a utilização de magnésia na formulação de concretos tem se restringido a no máximo $10 \%$ em peso e em granulometrias grosseiras (acima de $40 \mu \mathrm{m})[3,4]$. Esse fato foi associado aos problemas que a adição de magnésia pode acarretar no processamento desses materiais, como redução de fluidez e danos mecânicos devido à expansão volumétrica que acompanha sua reação de hidratação. Outros trabalhos, no entanto, sugerem que se essas dificuldades forem contornadas ou reduzidas, um novo salto no desenvolvimento tecnológico pode ser obtido $[1,2]$.

\section{Mecanismos de hidratação do $\mathrm{MgO}$ e técnicas de avaliação empregadas}

A hidratação do $\mathrm{MgO}$ consiste na exposição desse material à água ou vapor. As reações que descrevem esse processo são [5-10]:

$$
\begin{aligned}
& \mathrm{MgO}+\mathrm{H}_{2} \mathrm{O} \rightarrow \mathrm{Mg}(\mathrm{OH})_{2} \\
& \mathrm{MgO}+\mathrm{H}_{2} \mathrm{O}+\mathrm{CO}_{2} \rightarrow \mathrm{MgO}+\mathrm{H}_{2} \mathrm{CO}_{3} \rightarrow \mathrm{MgCO}_{3}
\end{aligned}
$$

O hidróxido de magnésio ou brucita, resultante da equação A é cristalino e pode ser detectado por meio de difração de raios X ou espectroscopia de infravermelho. Sua formação ocorre preferencialmente quando há grande disposição de água no meio (como na estrutura do concreto) [8-10]. Esse processo causa um aumento do $\mathrm{pH}$ que favorece a dissolução de $\mathrm{CO}_{2}$ na água levando à formação de ácido carbônico, $\mathrm{H}_{2} \mathrm{CO}_{3}$. Esse ácido ataca o $\mathrm{MgO}$ formando carbonato de magnésio ou magnésia (equação $\mathrm{B}$ ), de aspecto similar a uma camada de bolor. Essa reação ocorre principalmente em sínteres estocados por longos tempos e em peças prémoldadas expostas ao ar [8-10].

No ambiente industrial, ambas reações podem acontecer simultaneamente e causarem efeito similar: uma expansão volumétrica da ordem de duas vezes e meia, capaz de gerar tensões que tornam um produto pré-moldado sólido em uma massa disforme e quebradiça. No entanto como a magnesita $\left(\mathrm{MgCO}_{3}\right)$ se forma preferencialmente em superfícies expostas ao ar, a formação do hidróxido de magnésio é considerada como a principal responsável pela expansão volumétrica e seus efeitos sobre as propriedades dos refratários.

Devido a natureza policristalina da maioria dos óxidos de magnésio empregados como matéria prima em refratários, o processo de hidratação geralmente ocorre em duas etapas [6]. Inicialmente, a região dos contornos de grão é preferencialmente atacada devido à sua maior energia livre. Quando a primeira camada de hidróxido se forma, sua expansão volumétrica gera tensões que rompem as ligações no contorno de grão. Esse processo é conhecido como tempo de indução da hidratação e aumenta significativamente a área superficial disponível para reagir.

Com a evolução da reação, unidades cristalinas cada vez menores vão sendo formadas até que restem somente

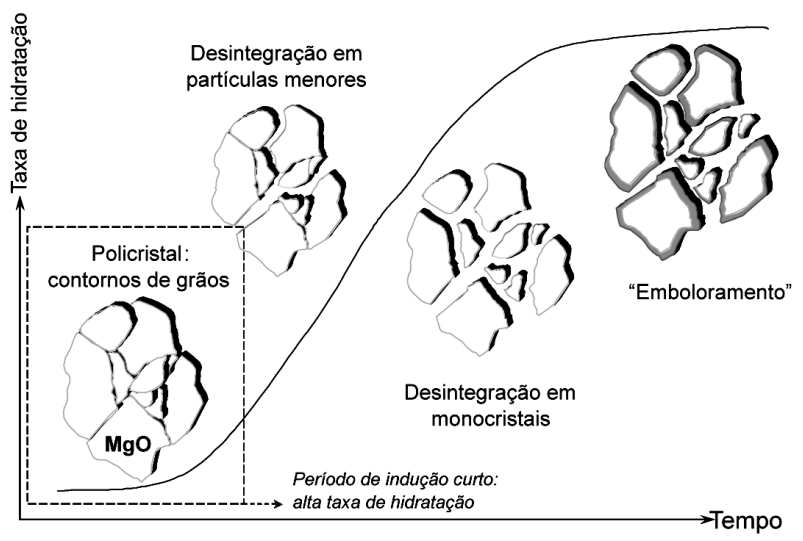

Figura 2: Mecanismo de hidratação do $\mathrm{MgO}$ policristalino. [Figure 2: Crystalline $\mathrm{MgO}$ hydration mechanism.] 
monocristais. Devido à sua elevada estabilidade química, o processo de hidratação dos monocristais é mais lento, já que a água é obrigada a atravessar uma camada de hidróxido para atingir o óxido. Nesse ponto o processo se torna dependente da velocidade de difusão e o crescimento dos cristais de hidróxidos ocorre continuamente em direção ao centro do cristal.

A resistência ou tendência à hidratação de sínteres de $\mathrm{MgO}$ e de refratários à base de $\mathrm{MgO}$ pode ser avaliada em testes de hidratação que consistem em expor esses materiais a diversas condições de umidade e temperatura, por diferentes períodos de tempo [5-11]. Em seguida, a quantidade de produtos formada é comparada com o valor previsto pela estequiometria da reação. O grau de hidratação ( $\alpha$, de 0 a 1) pode ser calculado pela equação:

$$
\alpha=\left(\frac{\Delta \mathrm{m}}{\mathrm{m}_{\mathrm{i}}}\right) \times\left(\frac{1}{0,45}\right)
$$

onde $\Delta \mathrm{m}$ é variação de massa, $\mathrm{m}_{\mathrm{i}}$ é a massa inicial e o termo $(1 / 0,45)$ é o valor teórico de $\alpha$ se a reação ocorresse totalmente.

Uma das condições mais utilizadas para determinação de $\alpha$ é o ensaio de autoclave, onde a amostra é aquecida em temperatura variando desde $70{ }^{\circ} \mathrm{C}$ [5] a $200{ }^{\circ} \mathrm{C}$ [6] em um vaso fechado, contendo atmosfera saturada de vapor de água. Calculado $\alpha$ para diferentes tempos de exposição a várias temperaturas pode-se construir um mapa de hidratação. Essa ferramenta pode ser bastante útil na determinação das condições ideais de secagem, mantendo a temperatura do processo abaixo dos valores críticos.

Os produtos formados nos testes de hidratação podem ser quantificados por meio de várias técnicas. A intensidade dos picos de difração de raios $\mathrm{X}$, de espectroscopia de infravermelho e termogravimetria permitem identificar e quantificar a formação de brucita e magnesita [8-10]. O acompanhamento do módulo elástico ultra-sônico do material em uma determinada condição de hidratação identifica o tempo necessário para que suas propriedades mecânicas comecem a se deteriorar [12].

Embora essas técnicas tenham permitido compreender melhor o mecanismo de hidratação do $\mathrm{MgO}$, os produtos formados e os fatores que mais influenciam a reação, nenhuma delas foi aplicada a concretos refratários (ou mesmo em suspensões aquosas) contendo magnésia. Por se tratar de sistemas muito mais complexos que as amostras de sínter moído e por envolver outras reações (como a hidratação do ligante), matérias primas e aditivos (dispersantes, modificadores de pega, surfactantes, entre outros), é razoável imaginar que os testes de hidratação e suas quantificações produzam resultados muito distintos dos encontrados na literatura.

\section{Técnicas anti-hidratação:}

Algumas técnicas descritas na literatura sugerem que sua utilização poderia reduzir a velocidade de hidratação e seus efeitos nas propriedades dos refratários. Algumas delas são descritas a seguir e criticamente analisadas.

\section{1 - Controle das impurezas em MgO policristalino [4]}

Como demonstrado no mecanismo de hidratação de policristais, contornos de grãos são regiões de elevada susceptibilidade à hidratação. Na tentativa de reduzir esse feito, impurezas de baixo ponto de fusão e com pouca ou nenhuma tendência a se hidratar (principalmente, $\mathrm{B}_{2} \mathrm{O}_{3}$, em teores até $1 \%$ peso) têm sido adicionadas em composições de $\mathrm{MgO}$ policristalino. Durante a calcinação $\left(900{ }^{\circ} \mathrm{C}\right)$, as impurezas fundidas são expulsas das estruturas internas dos cristais e se concentram nos contornos, formando um recobrimento protetor. Embora a hidratação tenha sido totalmente interrompida (em teores acima de 0,5\% peso), a redução de refratariedade dos materiais onde essa técnica foi aplicada se mostra como um importante efeito colateral negativo.

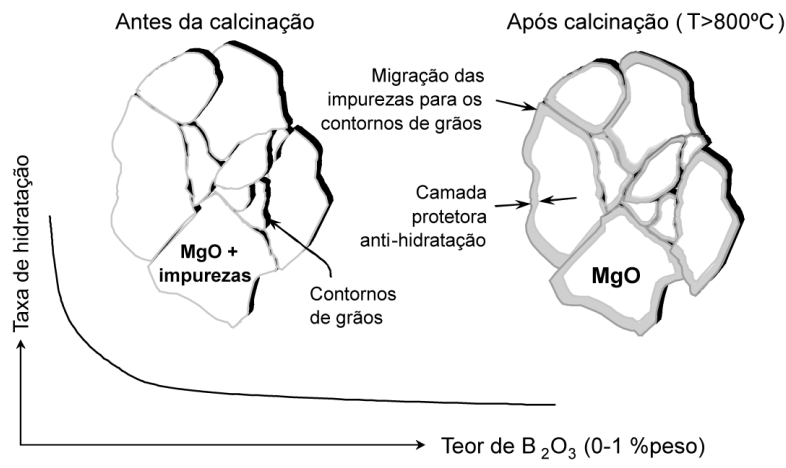

Figura 3: Efeito da presença de impurezas na velocidade de hidratação do $\mathrm{MgO}$.

[Figure 3: Effect of impurities on $\mathrm{MgO}$ hydration rate.]

2- Recobrimento das partículas de $\mathrm{MgO}$ com barreiras hidrofóbicas [13-14]

Baseada no princípio de que, sem água não pode ocorrer hidratação, essa técnica consiste em tratar as partículas de $\mathrm{MgO}$ com organosilanos. Esses agentes promovem a formação de uma barreira contínua na superfície dos materiais tratados. Dependendo do tipo utilizado, ela pode ser hidrofílica ou hidrofóbica, como no caso do $\mathrm{MgO}$.

Novamente, a total interrupção da reação de hidratação em água foi observada. No entanto, estudos referentes a mecanismosdeanti-hidrataçãoparapódealumínio, mostraram que o ambiente encontrado nos concretos refratários é extremamente agressivo a esse tipo de recobrimento, tanto pelo elevado $\mathrm{pH}$ (que dissolve a camada formada) quanto pelo cisalhamento durante misturas e bombeamento (que a remove). Devem ainda ser considerados os elevados custos que esses reagentes e seu processamento envolvem. 


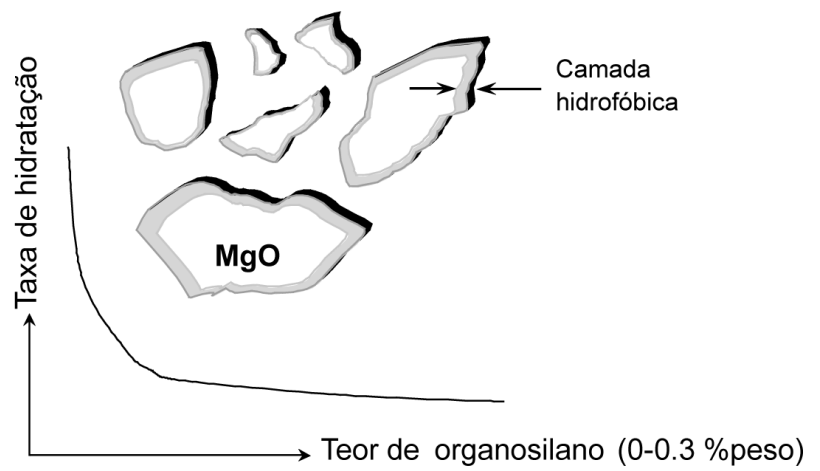

Figura 4: Efeito de recobrimento hidrofóbico na velocidade de hidratação do $\mathrm{MgO}$.

[Figure 4: Effect of hydrophobic coating on MgO hydration rate.]

\section{3- Substituição do MgO por espinélio pré-formado [15-17]}

Um dos grandes objetivos da adição de $\mathrm{MgO}$ a refratários de alta alumina é a formação de espinélio $\left(\mathrm{MgAl}_{2} \mathrm{O}_{4}\right)$. Essa fase apresenta excelentes propriedades, tais como elevada refratariedade e resistência à corrosão e ao choque térmico. Sua geração pode ocorrer de duas formas: 1) in situ: na microestrutura do refratário, durante o uso, ou 2) préformada: reação em fornos elétricos ou a gás, sendo que o produto resultante após moagem é inserido nas formulações de refratários.

A pré-espinelização do $\mathrm{MgO}$ reduz significativamente sua tendência à hidratação e os diversos problemas que sua adição às formulações geram (perda de fluidez e tempo de trabalhabilidade e expansão volumétrica). No entanto, o desempenho dos refratários formulados com esse tipo de espinélio não atinge os mesmo patamares daqueles onde ocorreu a espinelização in-situ. Isso porque, quando a reação ocorre no material, verifica-se uma maior densificação da estrutura, reduzindo a porosidade e a permeabilidade e gerando tensões internas de compressão, que atuam como mecanismo tenacificador. Além disso, esse processo é energeticamente mais favorável pelo menor número de operações unitárias envolvidas.

\section{4- Aditivos anti-hidratação [18-20]}

Alguns aditivos foram testados como inibidores de hidratação em suspensões de sínter de $\mathrm{MgO}$ e em concretos contendo $\mathrm{MgO}$. Devido à falta de sistematização desses estudos, não se pode atribuir à adição de substâncias como lactato de aluminio, $\mathrm{NaF}, \mathrm{NaCl}, \mathrm{CaF}_{2}, \mathrm{MgCl}_{2}, \mathrm{Al}_{2} \mathrm{O}_{3}, \mathrm{Cr}_{2} \mathrm{O}_{3}$,

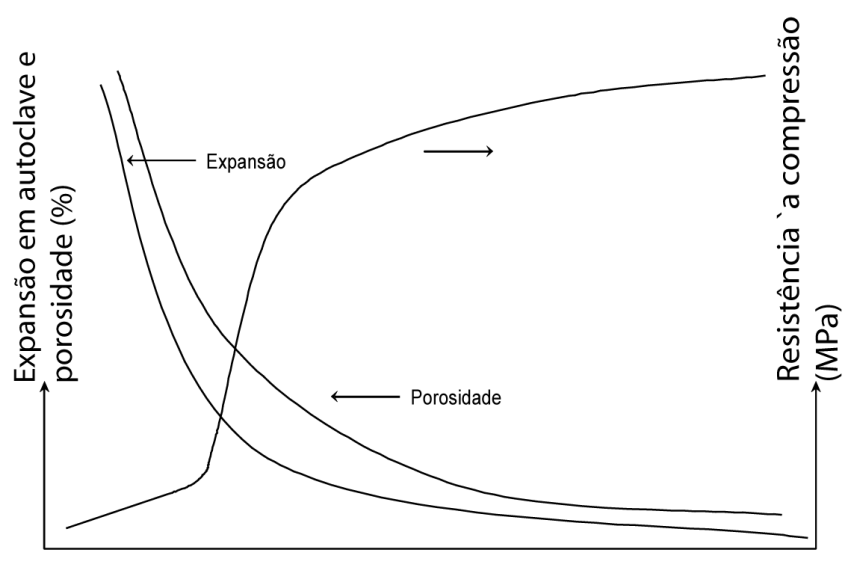

Teor de microssílica (0 -20\%peso)

Figura 5: Efeito da adição de microssílica na velocidade de hidratação do $\mathrm{MgO}$.

[Figure 5: Effect of microssílica addition on MgO hydration rate.]

Tabela I - Comparação de alguns aspectos da espinelização in-situ e da utilização de espinélio pré-formado em concretos refratários.

[Table - Relationship between in-situ spinelization and pre-formed spinel in refractory castables.]

\begin{tabular}{|c|c|c|}
\hline Espinelização in situ & Espinélio pré-formado & Observações \\
\hline Baixa fluidez & Boa fluidez & $\begin{array}{l}\text { Os estudos consultados } \\
\text { não utilizaram técnicas de } \\
\text { caracterização adequadas }\end{array}$ \\
\hline Grande tendência à hidratação & Quase nenhuma hidratação observada & - \\
\hline $\begin{array}{l}\text { Maior densificação, menor } \\
\text { expansão volumétrica }\end{array}$ & $\begin{array}{l}\text { Em excesso, pode } \\
\text { danificar a estrutura }\end{array}$ & $\begin{array}{l}\text { No processo in situ, há uma melhor } \\
\text { acomodação da estrutura formada }\end{array}$ \\
\hline $\begin{array}{l}\text { Magnésia apresenta grande } \\
\text { susceptibilidade à presença de } \\
\text { impurezas }\left(\mathrm{B}_{2} \mathrm{O}_{2} \text { and } \mathrm{Fe}_{2} \mathrm{O}_{3}\right)\end{array}$ & $\begin{array}{l}\text { Uma vez formado, o espinélio } \\
\text { pode absorver sem perda } \\
\text { de refratariedade }\end{array}$ & - \\
\hline $\begin{array}{c}\text { Elevada resistência à corrosão } \\
\text { e choque térmico }\end{array}$ & $\begin{array}{l}\text { Formação de trincas durante a expansão } \\
\text { pode aumentar a permeabilidade }\end{array}$ & $\begin{array}{l}\text { Trincas também podem ocorrer } \\
\text { na hidratação da magnésia }\end{array}$ \\
\hline
\end{tabular}

Em ambos os casos: excesso de magnésia na estequiometria da reação facilita o processo de sinterização 
$\mathrm{Fe}_{2} \mathrm{O}_{3}, \mathrm{TiO}_{2}$ e $\mathrm{ZrO}_{2}$ a redução de hidratação. Em alguns casos, por exemplo, $\mathrm{TiO}_{2}$ e $\mathrm{ZrO}_{2}$, as espécies adicionadas não são dissociáveis em água (no intervalo de alguns dias) e por isso dificilmente podem afetar o desenvolvimento da hidratação do $\mathrm{MgO}$.

Em estudos mais consistentes, foi verificado que a adição de microssílica (até $20 \%$ peso) em concretos levou a uma redução significativa na expansão volumétrica desses materiais. Esse fato pode ser atribuído à elevação da resistência mecânica que ocorre devido ao aumento da eficiência de empacotamento promovida pela microssílica. No entanto, a diminuição das conseqüências da hidratação (expansão) não necessariamente significa menor grau de hidratação.

\section{CONCLUSÕES}

De forma geral, pode-se afirmar que os mecanismos de hidratação da magnésia foram bem documentados e explicados nas publicações pesquisadas. Igualmente satisfatório, foram os estudos sobre os benefícios da incorporação de magnésia à formulações de concretos refratários aluminosos visando a espinelização. Por outro lado, as dificuldades associadas à sua hidratação e os possíveis modos de preveni-la ainda permanecem pouco explorados. Os autores desse estudo identificaram como causas principais a falta de sistematicidade dos métodos de pesquisa empregados e a provável restrição de informações devido aos aspectos tecnológicos.

\section{AGRADECIMENTOS}

Os autores agradecem à FAPESP, à Alcoa Alumínio e à Magnesita S.A. pelo suporte fornecido a esse trabalho.

\section{REFERÊNCIAS}

[1] R. Salomão, V. C. Pandolfelli, "Magnesia containing refractory castables (MCRF): an overview of 30 years of research and development", Am. Ceram. Soc. Bull. (2005) submetido.

[2] C. M. Peret, J. A. Gregolin, L. I. L Faria, V. C. Pandolfelli, "Patent generation and the technological development of refractories and steelmaking", Refractories Applications and News (2005) submetido.

[3] A. Nishikawa, "Technology of monolithic refractories", Tokyo: Technical Report No. 33-7, Plibrico Japan Co. Ltd. (1984) 98-101.

[4] A. Yoschida, T. Nemoto, A. Kaneyasu, "Evaluation method for hydration resistance of magnesia fine powder and effect of $\mathrm{B}_{2} \mathrm{O}_{3}$ content in magnesia raw materials", Proc. UNITECR' 03, Osaka (2003) 433-436.
[5] G. K. Layden, G. W. Brindley, "Kinetics of vapor-phase hydration of magnesium oxide", J. Am. Ceram. Soc. 46, 11 (1963) 518-522.

[6] A. Kitamura, K. Onizuka, K. Tanaka, "Hydration characteristics of magnesia", Taikabutsu Overseas 16, 3 (1995) 3-11.

[7] A. Kaneyasu, S. Yamamoto, A. Yoshida, "Magnesia raw materials with improved hydration resistance", Taikabutsu Overseas 17, 2 (1996) 21-26.

[8] P. Brandão, G. E. Gonçalves, A. K. Duarte, "Mechanisms of hydration / carbonation of basic refractories - Part I", Refr. Appl. News 3, 2 (1998) 6-9.

[9] P. Brandão, G. E. Gonçalves, A. K. Duarte, "Mechanisms of hydration / carbonation of basic refractories - Part II: Investigation of the kinetics of formation of brucite in fired basic bricks", Refr. Appl. News 3, 2 (1998) 9-11.

[10] P. Brandão, G. E. Gonçalves, A. K. Duarte, "Mechanisms of hydration / carbonation of basic refractories - Part III", Refr. Appl. News 8, 6 (1998) 23-26.

[11] S. Chatterji, "Mechanism of expansion of concrete due to the presence of dead-burnt $\mathrm{CaO}$ and $\mathrm{MgO}$ ", Cem. Conc. Res. 25, 1 (1995) 51-56.

[12] P. Lauzon, J. Rigby, C. Oprea, T. Troczynski, G. Oprea, "Hydration studies on magnesia-containing refractories", Proc. UNITECR' 03, Osaka (2003) 54-57.

[13] S. Zhang, S. Hashimoto, W.E. Lee, "Inhibiting hydration of aluminum powder using $\mathrm{SiO}_{2}$ coatings", Refr. Appl. News $\mathbf{8}, 3$ (2003) 21-25.

[14] A. R. Studart, M. D. M. Innocentini, I. R. de Oliveira, V. C. Pandolfelli, "Reaction of aluminum powder with water in cement-containing refractory castables" J. Eur. Ceram. Soc. 25, 13 (2005) 3135-3143.

[15] W. Vance, G. MacZura, "Influence of magnesium aluminate spinels on the performance of steelplant castables", Refr. Appl. News 2, 2 (1997).

[16] T.A. Bier, C. Parr, C. Revais, M. Vialle, "Spinel forming castables: physical and chemical mechanisms during drying", Refr. Appl. News 5, 4 (2000) 3-4.

[17] A. Gosh, R.Sarkar, B. Mukherjee, S.K. Das, "Effect of spinel content on the properties of magnesia-spinel composite refractory", J. Eur. Ceram. Soc. 24 (2004) 2079-2085.

[18] Y. Koga, M. Sato, K. Sekeguchi, S. Iwamoto, "Effects of alumina cement grade and additives on alumina-magnesia castable containing aluminum lactate", Taikabutsu Overseas 18, 1 (1997) 43-47.

[19] S. Chen, G. Chen, J. Cheng, "Effect of additives on the hydration resistance of materials synthesized from magnesia-calcia system", J. Am. Ceram. Soc. 83, 7 (2000) 1810-1812.

[20] M. M. Ali, A. K. Mullick, "Volume stabilization of high $\mathrm{MgO}$ cement: effect of curing conditions and fly ash addition", Cem. Conc. Res. 28, 1 (1998) 1585-1594.

(Rec. 30/05/2005, Ac. 21/10/2005) 